\title{
Recycled Tire Chips Mixed with Sand as Lightweight Backfill Material in Retaining Wall Applications: An Experimental Investigation
}

\author{
S. Bali Reddy ${ }^{1}$ (D) A. Murali Krishna ${ }^{1}$
}

Received: 18 August 2015/ Accepted: 20 September 2015/Published online: 23 October 2015

(c) Springer International Publishing AG 2015

\begin{abstract}
This paper presents studies on use of recycled tire shreds in sand-tire chips (STC) mixture for retaining wall applications. Small-scale physical model tests were performed on rigid retaining wall with different STC mixtures. Rigid retaining wall model of $600 \mathrm{~mm}$ height was constructed in a Perspex container. The wall was made with hollow rectangular steel sections. STC mixtures with different tire chips proportions, such as 10, 20,30,40, and $50 \%$ along with pure sand were considered as backfill materials. Static surcharge load, up to $10 \mathrm{kPa}$, was applied using concrete blocks. Model wall behaviour in terms of displacements and earth pressures has been discussed for sand alone (control case) and STC mixtures as backfill materials. The experimental results indicate that the horizontal displacements and lateral earth pressures are reduced to about 50-60\% of that of control case by using STC mixtures which functioned as light weight backfill materials.
\end{abstract}

Keywords Retaining walls $\cdot$ Sand-tire chip (STC) mixtures $\cdot$ Displacements $\cdot$ Earth pressure $\cdot$ Surcharge pressure

S. Bali Reddy

balireddy23@gmail.com; sodom@iitg.ernet.in

A. Murali Krishna

amurali@iitg.ernet.in

1 Department of Civil Engineering, Indian Institute of Technology Guwahati, Guwahati 781039, India

\section{Introduction}

Earth retaining structures such as retaining walls, bridge abutments, bulk heads, braced excavation and mechanically stabilized walls play a very important role in public life. These civil engineering structures are being used in many infrastructural projects and are often being subjected to different loading conditions. Performances of retaining walls under static and seismic loading conditions depend upon the type of backfill soil. Generally, clean granular cohesionless backfill materials are preferred. However, new lightweight fills materials like shredded tire chips, geofoam, fly ash, plastic bottles etc. [1-5] are being explored as alternative backfill materials now-a-days. These lightweight materials are beneficial in reducing earth pressures and lateral displacements of the retaining walls.

Scrap tires are undesired urban waste and are increasing every year. In future, volume of waste tires is going to increase in significant amount in many developing countries. One possible way for this problem is to finding new and beneficial methods to recycle and reuse the large volumes of scrap tires. Re-use of scrap tires in civil engineering applications is essential step in creating a sustainable future. In some situations use of tire derived materials may provide greater economy than those materials traditionally used. Various researchers have carried out investigations on the usage of scrap tire derived materials in civil engineering applications like recycled tire chips as a fill material in road/ embankment construction [6-8], lightweight fill material in retaining wall backfill under static loading conditions [2-5], and waste tire shreds as a leachate collection layer $[9,10]$. Several researchers [11-22] have evaluated the engineering properties of the scrap tire chips and sand tire chip mixtures by conducting permeability, compressibility, large direct shear tests, and triaxial tests on the samples. The 
permeability and shear strength of the sand tire chip mixtures are higher than that of sand alone [18] and the unit weight of the tire chips is less than one third of that of sand [3] making them fit for light weight fill material.

A study carried out by Cecich et al. [3] explained the applicability of pure tire chips in retaining wall backfill by achieving the higher factors of safety against sliding, overturning compared to the sand as backfill under static loading conditions. Lee and Roh [23] proved that the dynamic earth pressures behind a retaining wall were reduced on using a backfill material having lesser elastic modulus and higher damping ratio and demonstrated that tire chips possesses these reliable properties. Xiao et al. [24] conducted reduced scale model tests on retaining walls of height $1.6 \mathrm{~m}$ backfilled with tire derived aggregate (TDA) under static and seismic loading conditions and compared the results with that of conventional sand as backfill. It has been found that the displacements of the wall, accelerations in the backfill soil, static and dynamic stresses in the backfill were reduced by using TDA due to the lesser unit weights and higher damping ratios of rubber materials. Numerical analysis on retaining walls backfilled with pure tire chips and pure sand carried out by Huggins and Ravichandran [25] and Ravichandran and Huggins [4] showed that the bending moments, shear forces and the displacements of the walls backfilled with tire chips were reduced significantly than that of walls backfilled with sand considered. Shaking table tests on gravity type model caisson with tire chips $[26,27]$ demonstrated that the tire chips acted as cushioning material and substantially reduced the seismic load against the caisson wall.

The literature indicates that most of the studies considered only pure tire derived materials or pure sand for retaining wall backfill applications. This paper presents the investigations on the use of recycled tire chips mixed with sand as light weight backfill material for retaining wall applications through a series of laboratory model tests. Model walls behaviour with different sand-tire chip (STC) mixtures, in terms of displacements and lateral earth pressures were presented.

\section{Test Cases and Program}

Two types of test cases were considered as shown in Fig. 1 . Case A, a retaining wall model with a conventional sandy backfill was used (control case); Case B, the model wall with different STC mixtures $(10,20,30,40$, and $50 \%$ of Tire chips) as backfill materials.

Six model tests (T1-T6) were conducted on retaining wall models with pure sand (STC0, control case) and different STC mixtures (STC10, STC20, STC30, STC40 and STC50) as backfill. The STC mixtures were prepared by mixing sand and tire chips in different proportions by weight, as shown in Table 1 . Static loading up to $10 \mathrm{kPa}$, in the form of concrete cubes, was applied to each model wall in multiples of $1 \mathrm{kPa}$. The test parameters for different model wall tests are given in Table 1 .
Fig. 1 Test case: a Case A: sandy backfill, b Case B: different STC mixtures backfill (a)

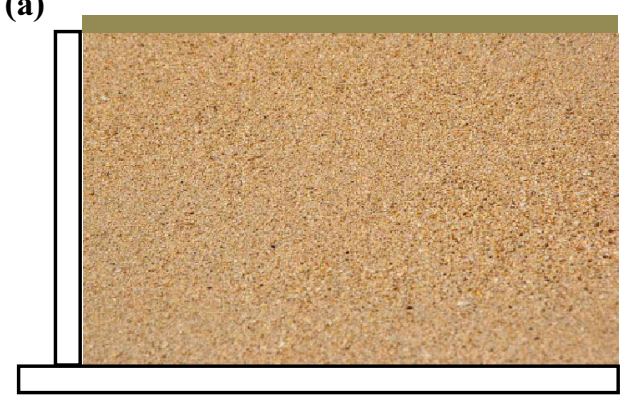

(b)

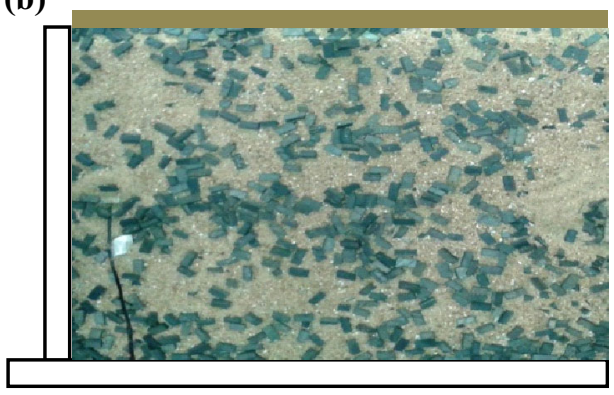

Table 1 Model test parameters

\begin{tabular}{lllll}
\hline Test no. & STC mixture & $\begin{array}{l}\% \text { TC } \\
\text { (by weight) }\end{array}$ & $\%$ Sand & Surcharge (kPa) \\
\hline T1 & STC0 & 0 & 100 & $0-10$ \\
T1-Repeated & STC0 & 0 & 100 & \\
T2 & STC10 & 10 & 90 & \\
T3 & STC20 & 20 & 80 & \\
T4 & STC30 & 30 & 70 & \\
T5 & STC40 & 40 & 60 & \\
T6 & STC50 & 50 & 50 & \\
\hline
\end{tabular}




\section{Materials Used}

In the current study, sand, tire chips and their mixtures were used as backfill materials in the retaining wall models.

\section{Sand}

Locally available cohesionless dry sand used in the model tests. Figure 2 shows the particle size distribution of the sand used in this study. The sand achieved maximum dry unit weight of $16.1 \mathrm{kN} / \mathrm{m}^{3}$ in a vibration test and the minimum dry unit weight observed in the loosest state was $13.26 \mathrm{kN} / \mathrm{m}^{3}$. Unit weight of the sand in the control case model wall (Test T1) was maintained at $15.57 \mathrm{kN} / \mathrm{m}^{3}$. Large size (shear box of $300 \times 300 \times 300 \mathrm{~mm}$ ) direct shear tests were conducted for sand with different normal stresses to finding the shear strength parameters. Figure 3 shows the direct shear results of sand at various normal stresses. The properties of sand are shown in Table 2.

\section{Sand-Tire Chips (STC) Mixtures}

Scrap tire derived tire chips (TC) of $10 \times 10 \mathrm{~mm}$ size and about $20 \mathrm{~mm}$ length (Fig. 4) have been used for the study. Specific gravity and unit weight of the tire chips were determined as 1.08 and $6.45 \mathrm{kN} / \mathrm{m}^{3}$, respectively. Tire chips were added to the sand, in percentage by the weight, different STC mixtures $(10,20,30,40$, and $50 \%)$ were prepared by manual mixing (Fig. 5) to maintain the selected TC percentage levels. Laboratory characterisation tests were carried out using different STC mixtures. For preparing a STC mixture, calculated amounts of sand and TC (as per the target proportion) were placed together and mixed manually to maintain the uniform mixture. Figure 6 shows the particle size distribution of the STC mixtures.

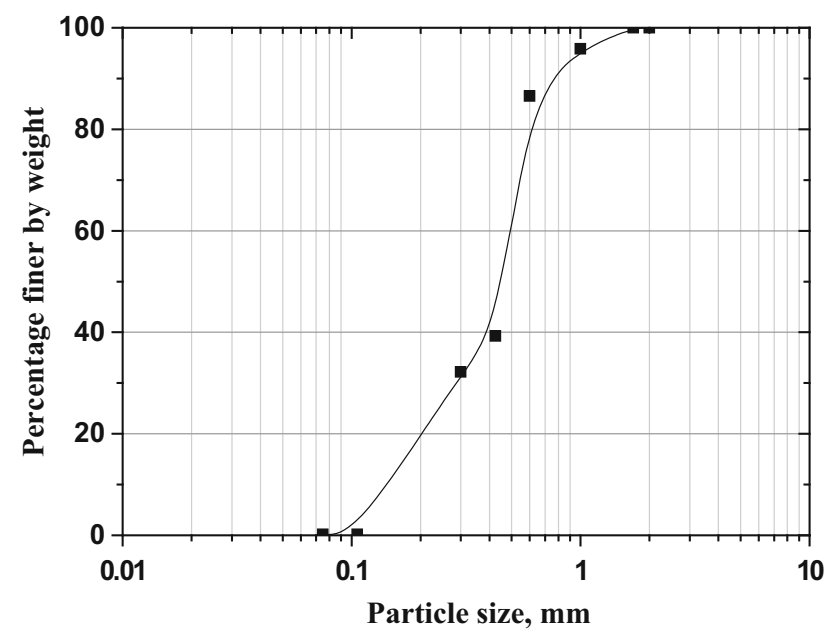

Fig. 2 Grain size distribution of the sand

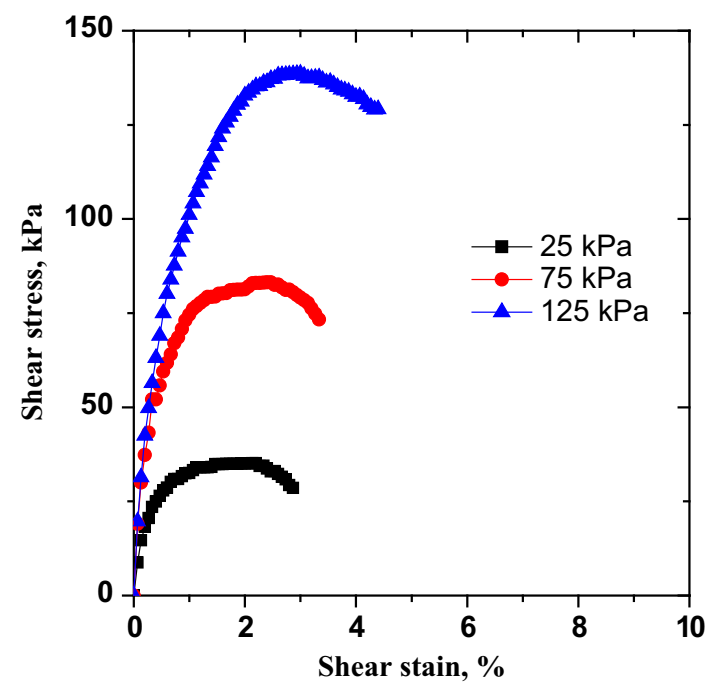

Fig. 3 Direct shear test results of the sand

Table 2 Properties of sand

\begin{tabular}{ll}
\hline Parameter & Value \\
\hline Specific gravity & 2.62 \\
Coefficient of curvature & 1.02 \\
Uniformity coefficient & 1.82 \\
$e_{\min }$ & 0.64 \\
$e_{\max }$ & 0.94 \\
Angle of internal friction $\left(^{\circ}\right)$ & 48 \\
USCS classification symbol & $\mathrm{SP}$ \\
\hline
\end{tabular}

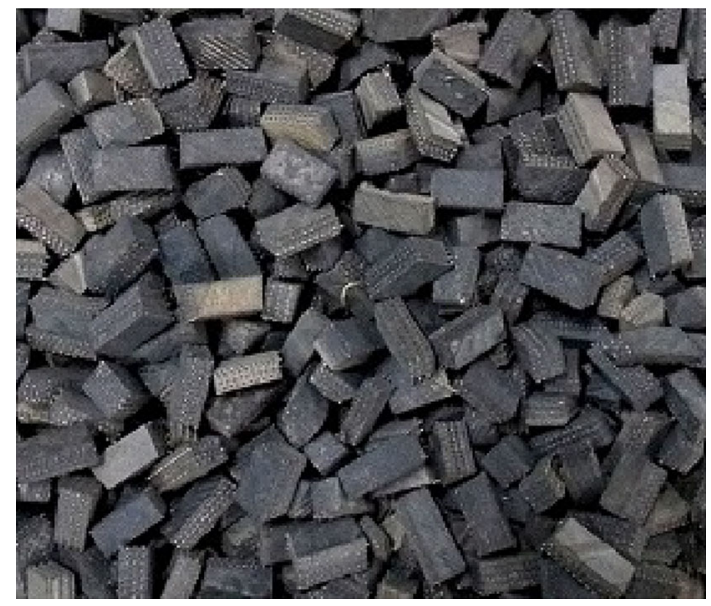

Fig. 4 Typical tire chips used in this study

Characterisation of different STC mixtures was presented by Reddy et al. [28] which are shown in Table 3. Void ratio of the STC mixtures (compacted and loose state) are calculated using dry unit weights and specific gravity values of the mixtures, which are plotted in Fig. 7. As seen in 


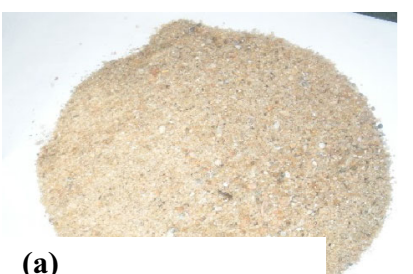

(a)
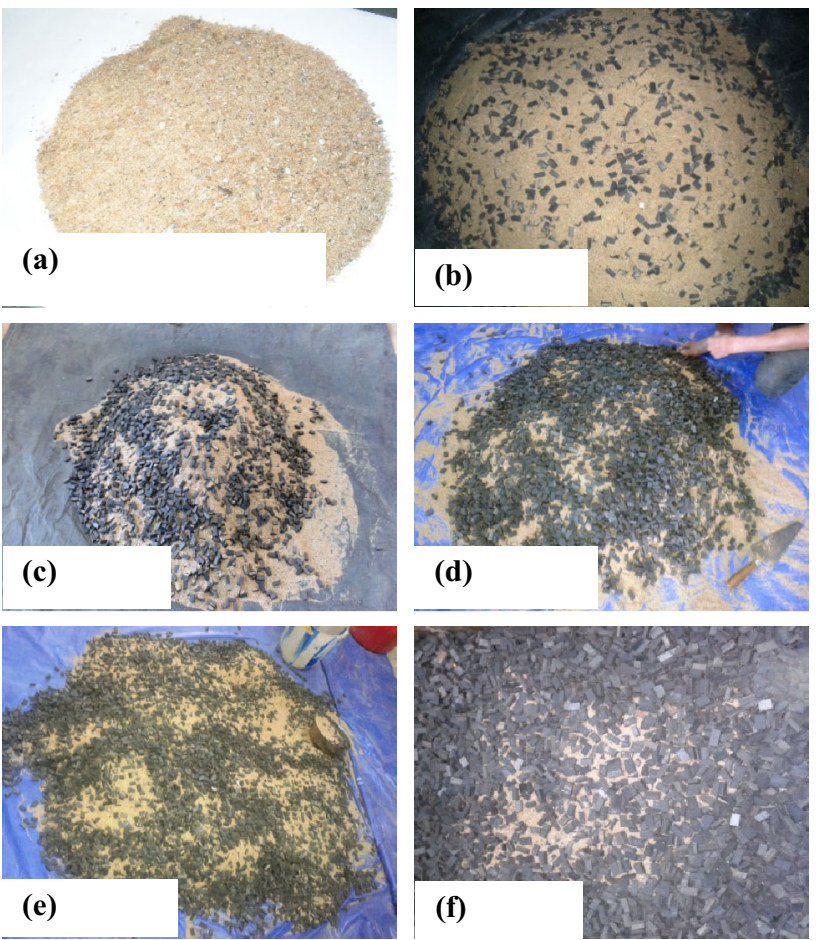

Fig. 5 STC mixtures. a STC0 (pure sand), b STC10, c STC20, d STC30, e STC40, f STC50

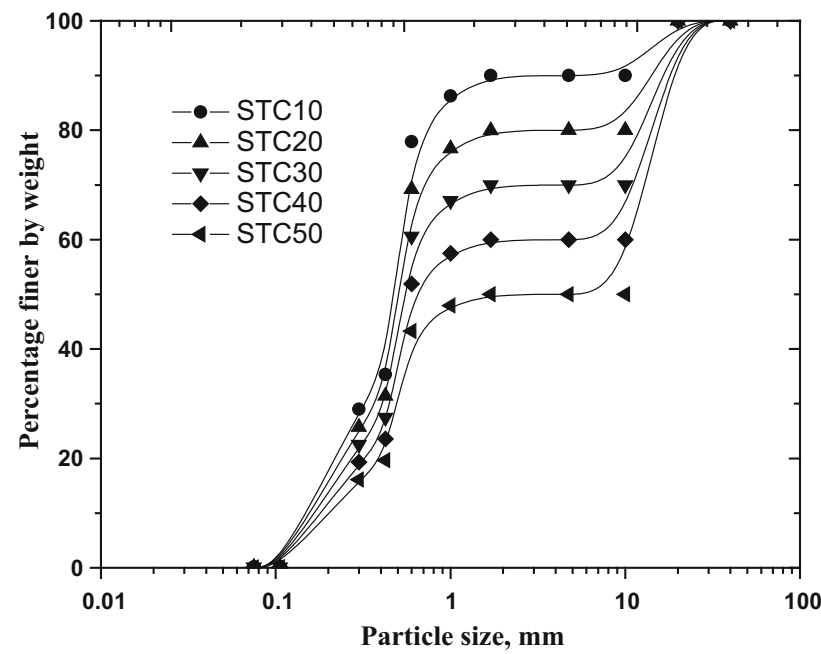

Fig. 6 Grain size distribution of the STC mixtures
Fig. 7, the void ratio is less at STC30 compared to STC20 and STC40. This indicates that STC30 is an optimum mixture wherein, most of the voids between the tires chips are filled with sand particles. Large direct shear test setup, having shear box of $300 \times 300 \times 300 \mathrm{~mm}$, was used to determine the shear strength properties of STC mixtures. Direct shear tests were conducted at three normal stresses of 25,75 , and $125 \mathrm{kPa}$ and the friction angles for different mixtures were evaluated (Table 3 ). It is observed from the Table that internal friction angle is high at STC30 compared to STC20 and STC40. Shear strength (friction angle) and deformability (void ratio) properties for different STC mixtures indicated that optimum percentage of STC mixtures would lie in the range of $30-40 \%$ of STC mixture.

\section{Model Construction and Instrumentation}

Retaining wall model of $600 \mathrm{~mm}$ height was constructed in a model container of $1200 \mathrm{~mm} \times 600 \mathrm{~mm}$ in plan and $1000 \mathrm{~mm}$ height (Fig. 8). The model container is made of Perspex sheets of $10 \mathrm{~mm}$ thickness and braced by a steel frame made of steel angle sections that also facilitates for easy lifting and handling. The model wall of $600 \mathrm{~mm}$ high

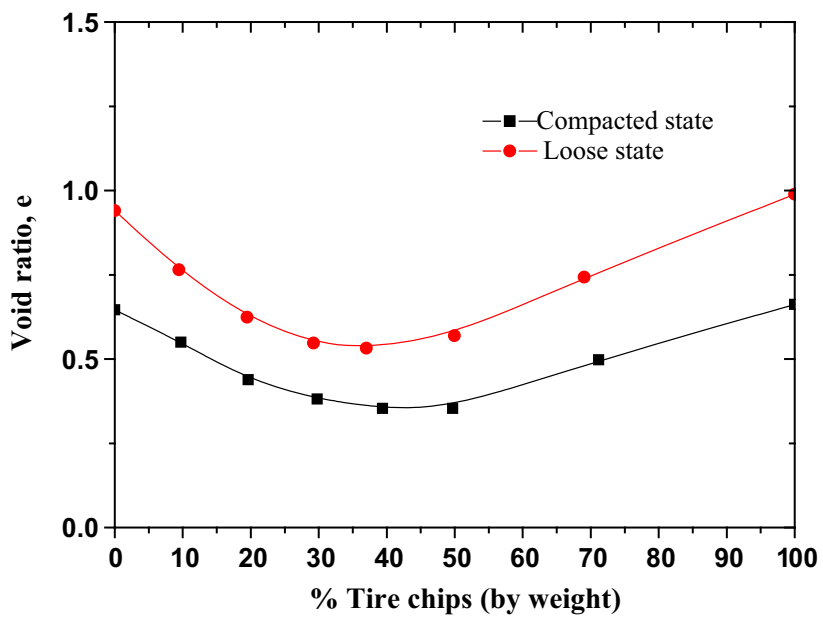

Fig. 7 Void ratio of the STC mixtures at loose and compacted state
Table 3 Properties of different STC mixtures

\begin{tabular}{llll}
\hline STC mixture & Specific gravity $(\mathrm{G})$ & Dry unit weight $\left(\mathrm{kN} / \mathrm{m}^{3}\right)$ & Angle of internal friction $\left(^{\circ}\right)$ \\
\hline STC10 & 2.25 & 14.62 & 51 \\
STC20 & 1.94 & 14.12 & 52 \\
STC30 & 1.82 & 13.17 & 56 \\
STC40 & 1.71 & 12.29 & 51 \\
STC50 & 1.53 & 10.42 & 44 \\
Pure tire chips & 1.08 & 6.45 & 28 \\
\hline
\end{tabular}




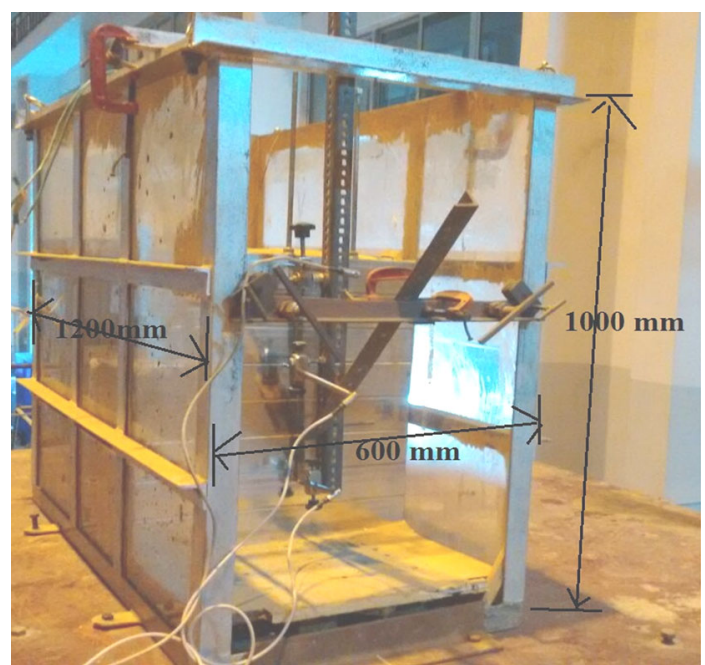

Fig. 8 Model container with typical model wall

and $580 \mathrm{~mm}$ length was made with eight hollow rectangular steel sections, each of $25 \mathrm{~mm}$ wide and $75 \mathrm{~mm}$ height and $580 \mathrm{~mm}$ length, which were joined together using steel rods of $12 \mathrm{~mm}$ diameter. These steel rods were further connected to a bottom plywood base forming a rigid connection. A typical wall after construction is shown in Fig. 8. Backfill of width $800 \mathrm{~mm}$ was adopted that was filled using sand or STC mixtures in different model tests. STC mixtures were prepared by manual mixing, by maintaining the selected TC percentage levels. After providing temporary support to the wall facing, backfilling was done in stage wise by free falling technique (placing the calculated amount of backfill material based on layer thickness and target density) and compacting manually to achieve the target density. A solid wooden platform has been placed on the surface of backfill to facilitate the surcharge application using concrete cubes. Figure 9 shows schematic of model wall configuration with concrete cubes used as surcharge pressure and the locations of the various instrumentations. To monitor the lateral deformation of the wall, linear variable differential transformers (LVDTs), L1, L2 and L3 were positioned on the front face of the wall at 186, 430, and $580 \mathrm{~mm}$ from the base of the wall, respectively. Four pressure sensors (each of $50 \mathrm{kPa}$ capacity), P1, P2, P3 and P4 are placed inside the wall, in contact with the facing at $487,337,187$, and $37 \mathrm{~mm}$ elevations from the top to measure horizontal soil pressures against the facing.

\section{Results and Discussions}

The model walls were tested with the sand alone and STC mixtures $(10,20,30,40$, and $50 \%$ of TC by weight) as a backfill material as presented in Table 1 . The retaining wall response was monitored after temporary support removal and after application of different surcharge loads. The results obtained are discussed in terms of horizontal displacements and lateral earth pressures in the following sections.

Fig. 9 Schematic diagram of test wall configuration

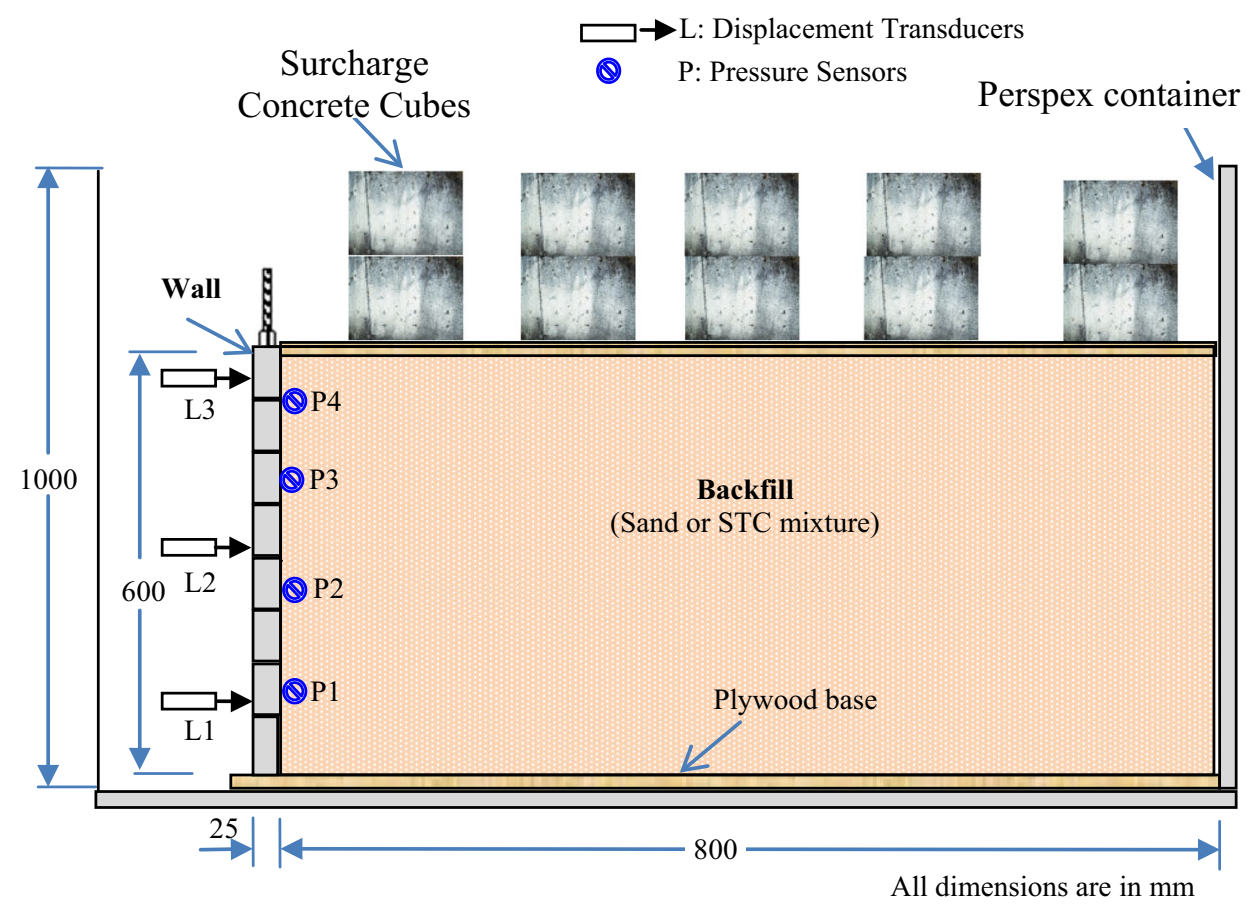




\section{Displacement Response}

\section{Without Surcharge Pressure}

The model wall was built with pure sand (control case) and various STC mixtures $(10,20,30,40$, and $50 \%)$ as backfill materials. Horizontal wall displacements along the height of the wall were monitored using three LVDTs positioned as shown in Fig. 9. Test $\mathrm{T} 1$ is repeated to verify the repeatability of the model test results. The horizontal wall displacements measured after the support removal (without surcharge loading) are shown in Fig. 10. Figure 10a shows the variation of horizontal displacements along the height of wall for all the model tests. For STC0 backfill tests, the horizontal displacements for the repeated tests are reasonably matched to each other confirming the repeatability of the tests. Maximum wall displacement is observed to be about $1.75 \mathrm{~mm}$ in this case. Among different tests, Test T4 with STC30 backfill showed lowest wall top displacement
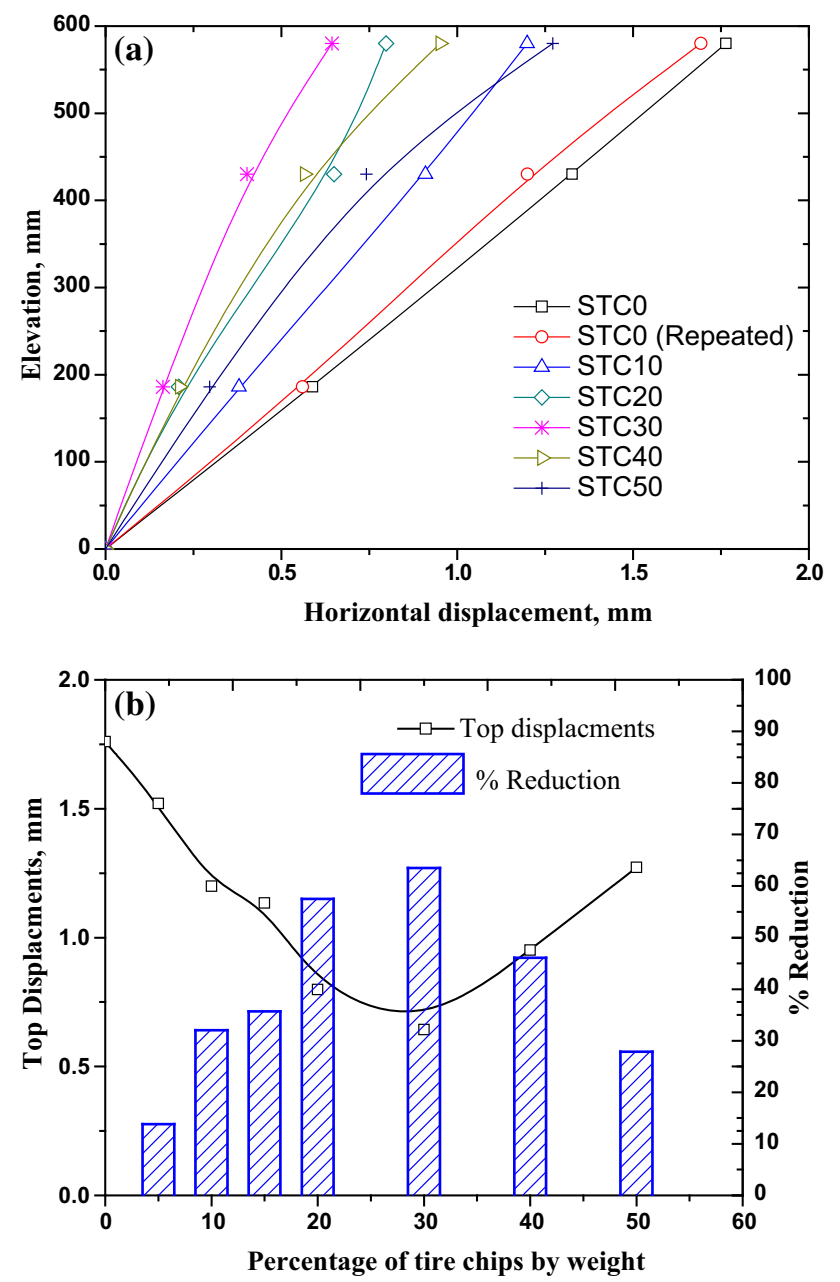

Fig. 10 Effect of STC mixture; a displacement profiles, b top displacements and $\%$ reduction as $0.65 \mathrm{~mm}$. Percentage reduction of displacements is calculated by using top displacements of control case and STC mixture values. Variations of the top displacement and its percentage reduction with reference to the control case (Test T1) with percentage tire chips are shown in Fig. 10b. It is revealed that $60-65 \%$ reduction in top displacements as compared to control case (Pure sand).

\section{With Surcharge Pressures}

The surcharge-pressures have been applied up to $10 \mathrm{kPa}$ on the backfill surface all the model walls, in multiples of $1 \mathrm{kPa}$, using concrete cubes as shown in Fig. 9. Figure 11 presents the displacements of model walls along the height for different surcharge pressures for control case (Pure sand) and STC30. It can be observed that, displacements are increased along the height of wall by increasing surcharge pressures as excepted. Maximum displacements at the top of the wall at $10 \mathrm{kPa}$ surcharge are noted as $6 \mathrm{~mm}$
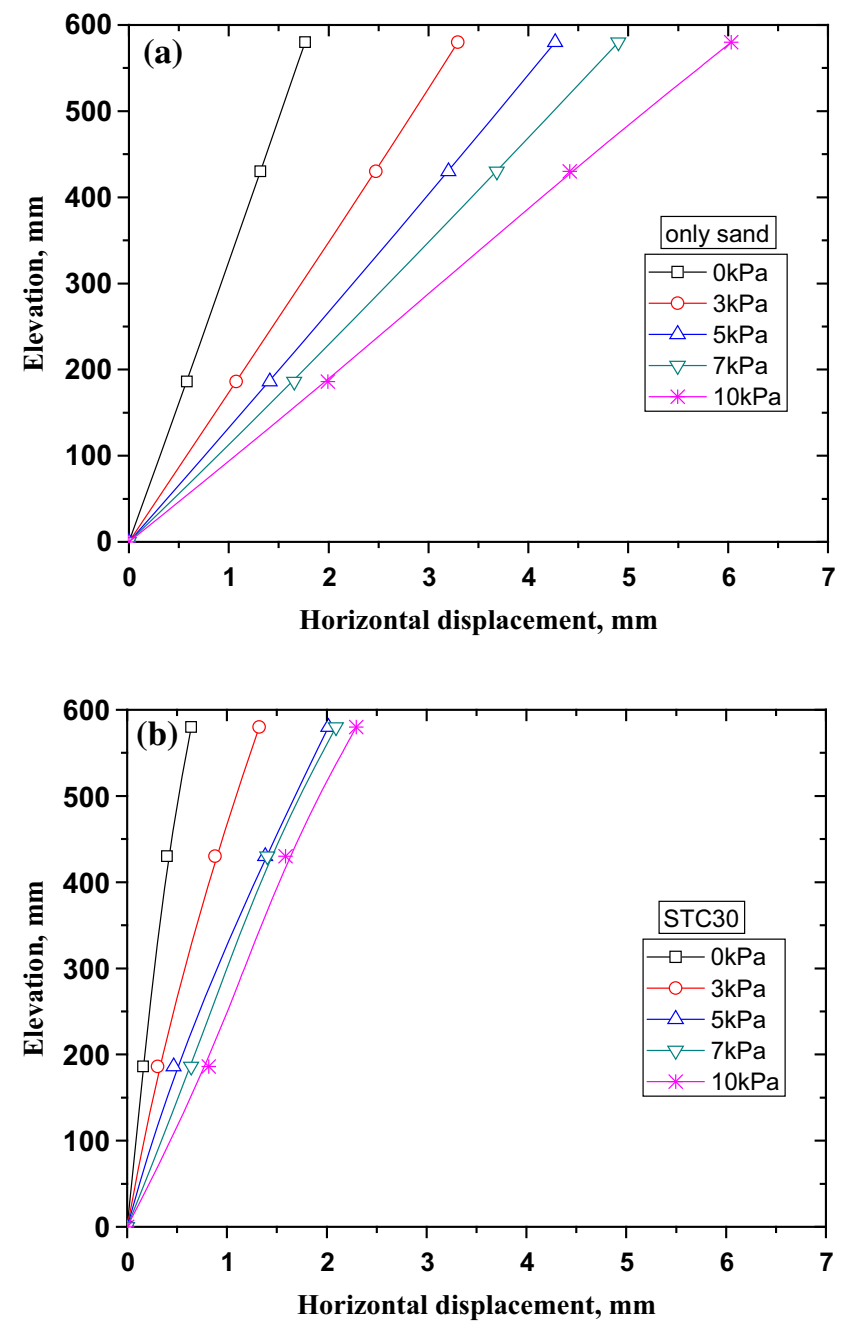

Fig. 11 Wall displacement profiles for different surcharge pressures: a For Test T1 (sand alone), b For Test T4 (STC30) 
and $2.4 \mathrm{~mm}$ for STC0 and STC30 backfill walls, i.e., Tests $\mathrm{T} 1$ and $\mathrm{T} 4$, respectively.

The top displacements of wall at different surcharge loading conditions in different tests with different STC mixtures are presented in Fig. 12. It is seen from the figure that the top displacements are increased with increasing surcharge pressures in all STC mixtures. The figure also depicts the fact that at all surcharge loading conditions the lowest displacements are shown for STC30 mixture and highest for the control case with STC0 backfill. Displacements in the range of 3.5-6 mm for STC0 are recorded for surcharge variation from 1 to $10 \mathrm{kPa}$. The corresponding displacements variations for STC30 are in the range of $0.5-1.1 \mathrm{~mm}$. Figure 13 presents the variation of wall top displacement at $10 \mathrm{kPa}$ surcharge for different STC mixtures (\%TC) and percentage reduction. Wall top displacements of $6,4.4,2.8,2.3,3.42$, and $4.3 \mathrm{~mm}$ are seen from the figure, for $0,10,20,30,40$ and $50 \%$ of tire chips, respectively. The top displacement displacements are

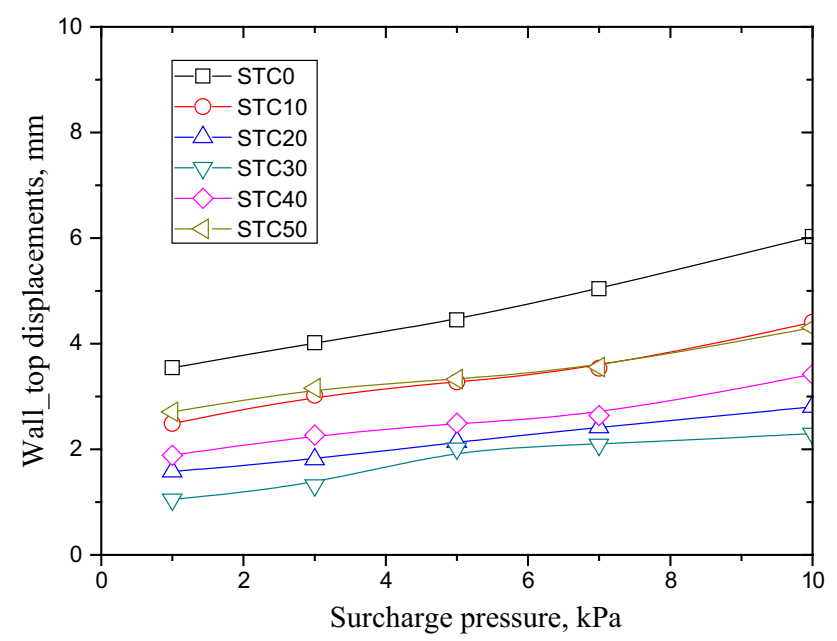

Fig. 12 Top displacements with surcharge pressures

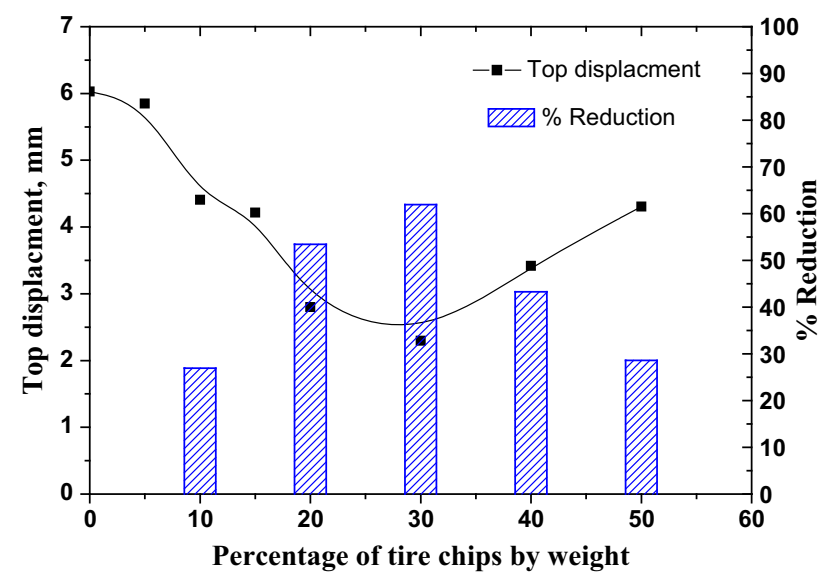

Fig. 13 Effect of STC mixture at $10 \mathrm{kPa}$ decreased by increasing tire chips content up to STC30. Beyond this \% $\mathrm{TC}$ further addition of TC resulted in increasing maximum lateral displacements. The percentage reduction in settlement is about $60 \%$ for STC 30 .

Referring to the Figs. 10, 11, 12, 13 it can be stated that wall displacements are reduced significantly (up to about $60 \%$ ) by addition of TC up to $30 \%$ by weight. The reason behind this displacement reduction is that, when tire chips content is increasing in the place of sand the unit weight was decreased (Table 3) due to the fact that TC has less specific gravity as compared to sand and a lower void ratio can be seen at STC30 (Fig. 7). Further, it can also be observed from Table 3 that addition of tire chips (up to $30 \%$ ) in sand increased the shear strength properties like angle of internal friction values.

\section{Lateral Earth Pressures}

Lateral earth pressures are monitored at two conditions (at rest and after support removal). Four Earth pressures sensors were placed at different elevations on the retaining wall for the purpose (Fig. 9). Figure 14 shows the earth pressure response under both the condition for all the model walls with different STC mixtures. Figure 14a shows the lateral earth pressures along the height of wall for at rest condition while, Fig. 14b for support removal condition. The figures indicate that lateral pressures fall in the range of $0-2 \mathrm{kPa}$ under both the conditions. Though there is no consistent trend in relative variations of pressures for different model walls, it can be observed that the pressures after support removal condition are low compared to the at rest condition. Further it can also be seen that the earth pressures were affected by the STC mixture giving lowest earth pressure for STC30 model (Test T4).
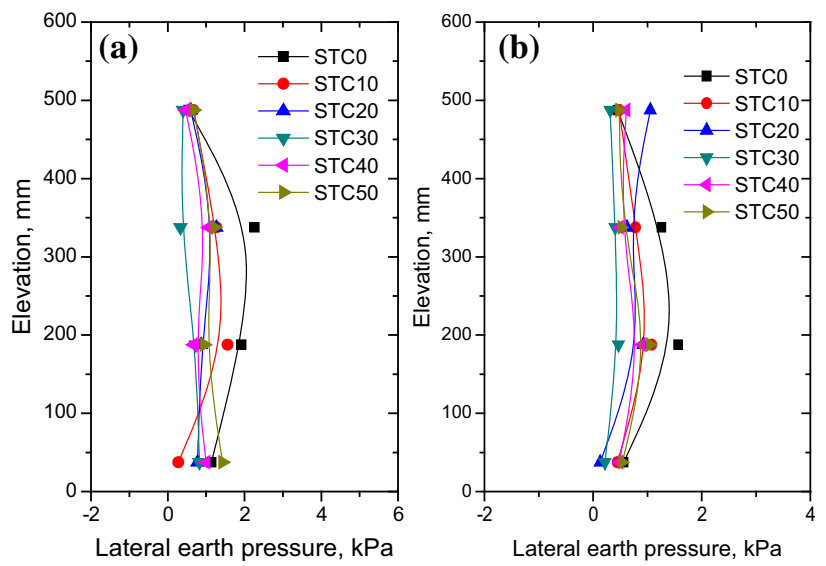

Fig. 14 Measured lateral earth pressures; a at rest condition, b After support removal 
Measured earth pressures are compared by using theoretical earth pressure evaluations. Pressures before support removal were compared with the pressure at at-rest condition (Eq. 1) and pressures after support removal are compared with active earth pressure condition (Eq. 2). It may be noted that, in fact, the pressures after support removal will be in between these two values.

$p_{\mathrm{o}}=(1-\sin \phi) \gamma z$

$p_{\mathrm{a}}=\frac{(1-\sin \phi)}{(1+\sin \phi)} \gamma z$ where $p_{\mathrm{o}}$ is the earth pressure at at-rest condition at an depth $z$ from the top of wall; $p_{\mathrm{a}}$ is the earth pressure at active condition at an depth $z$ from the top of wall; $\gamma$ and $\phi$ are the unit weight and angle of internal friction of backfill material under consideration.

Figures 15 and 16 shows the comparison of theoretical and measured earth pressures with different STC mixtures in both conditions. Measured earth pressures are close with theoretical maximum earth pressures in all STC mixtures as shown in Figs. 15 and 16. Under surcharge loading earth pressures are not discussed here due earth pressure sensors
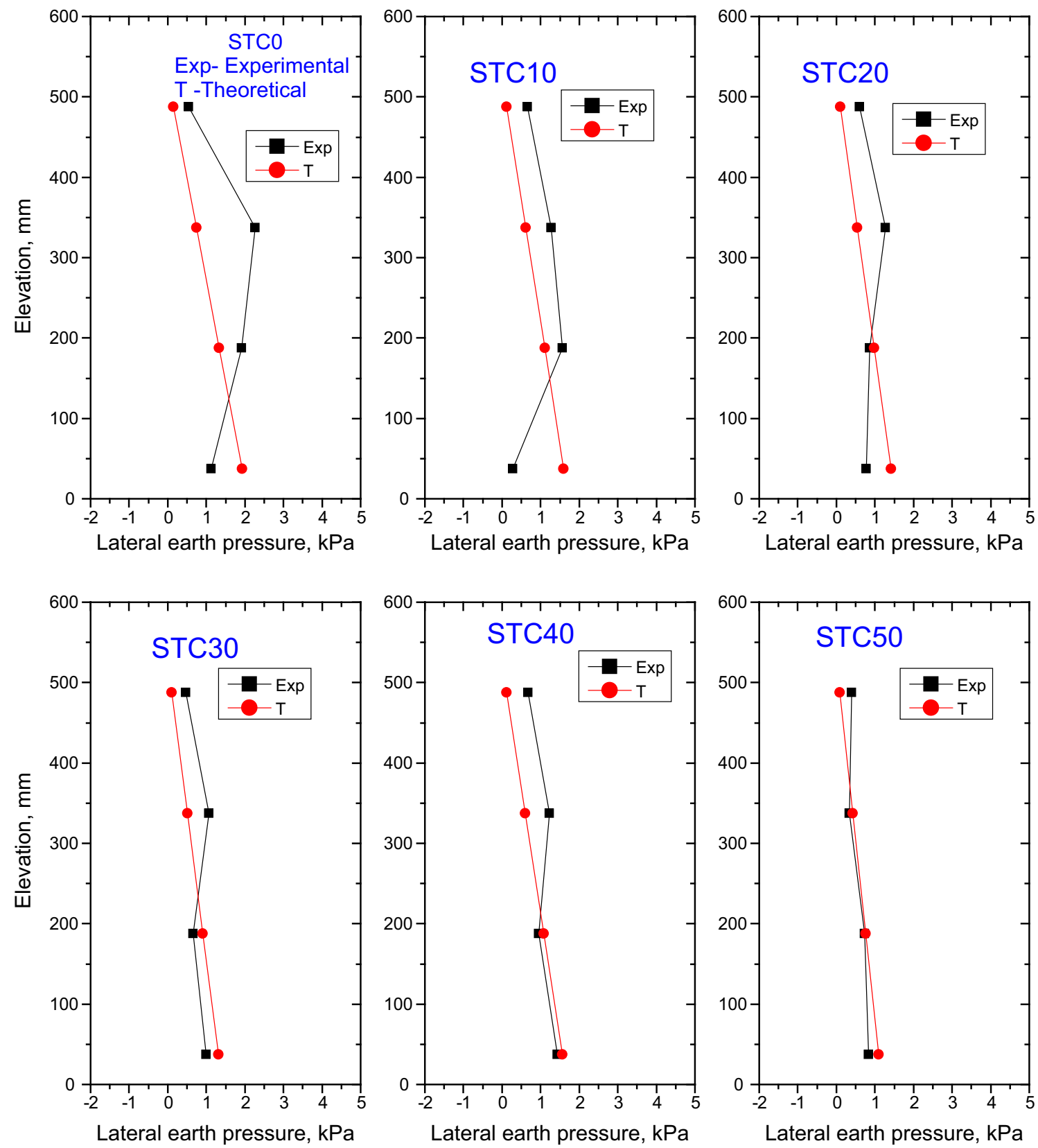

Fig. 15 Measured and theoretical lateral earth pressures at rest condition 

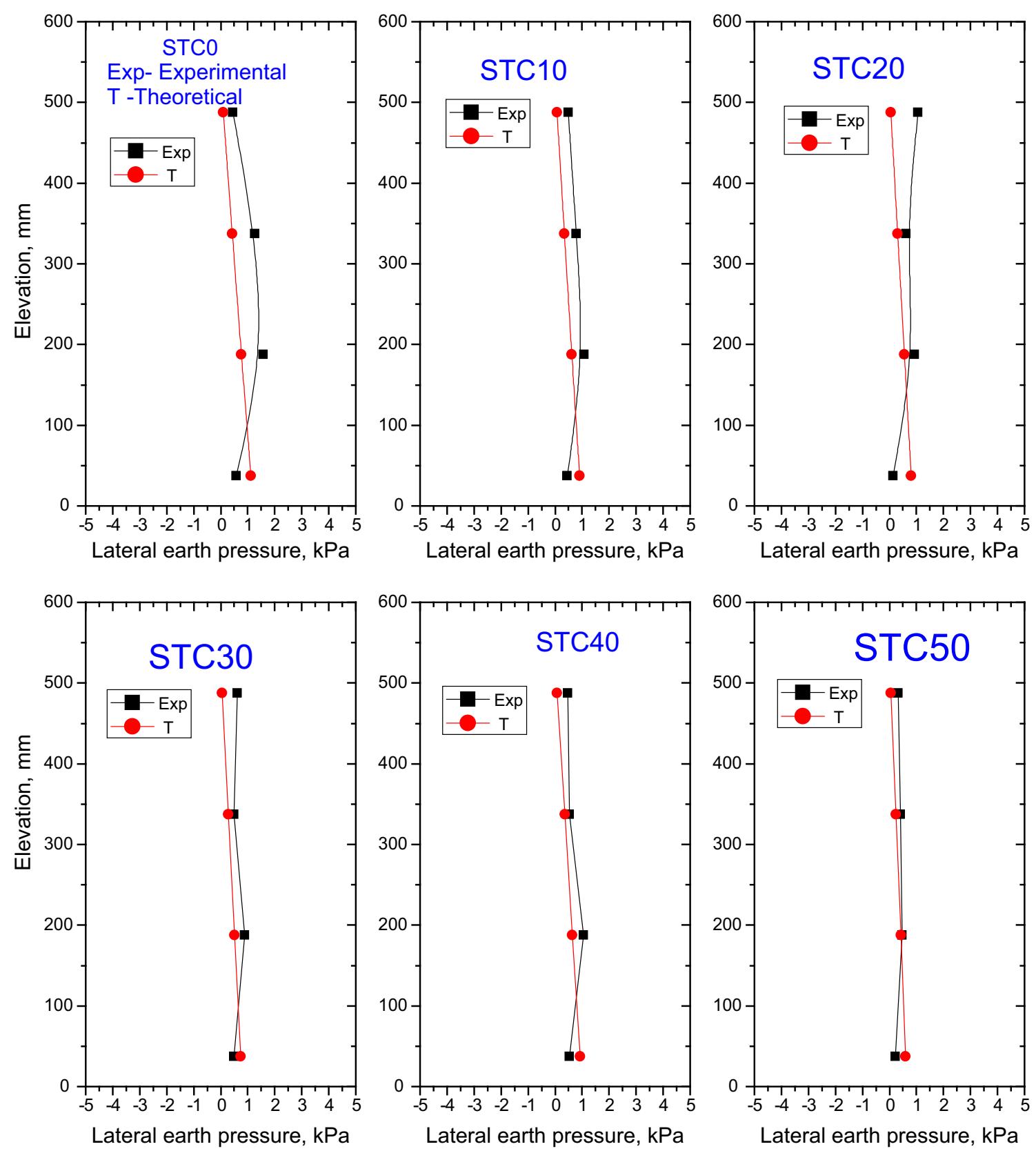

Fig. 16 Measured and theoretical lateral earth pressures active condition

are not given consistent results. Maximum values of earth pressures, measured along the height of the model wall, in each test were considered to evaluate the percentage reduction in lateral earth pressure values with addition of tire chips (TC). Percentage reduction of measured maximum earth pressures with \% tire chips is shown in Fig. 17. Percentage reduction of earth pressure was increased by increasing \% TC for model wall with STC30. By using STC30, it can be seen that about 50-60\% reduction in earth pressures.

The experimental results indicate that the horizontal displacements and lateral earth pressures are reduced in range of $50-60 \%$ by using STC30 mixture. Referring to Reddy et al. [28], higher shear strength properties (friction angle) and lower deformation properties (void ratio) can be seen at STC30. Moreover, the tire chips are being lighter, and depicting higher shear properties in the element tests are contributed to the observed response. Though unit weight of the STC mixture beyond STC30 is reducing, the reduced shear strength behaviour and increased deformation behaviour (void ratio) resulted to the detrimental effect of addition tire chips. The study shows the beneficial effect of mixing the tire chips in cohesionless backfill (sand) up to about $30 \%$ by weight would yield the beneficial effect. 


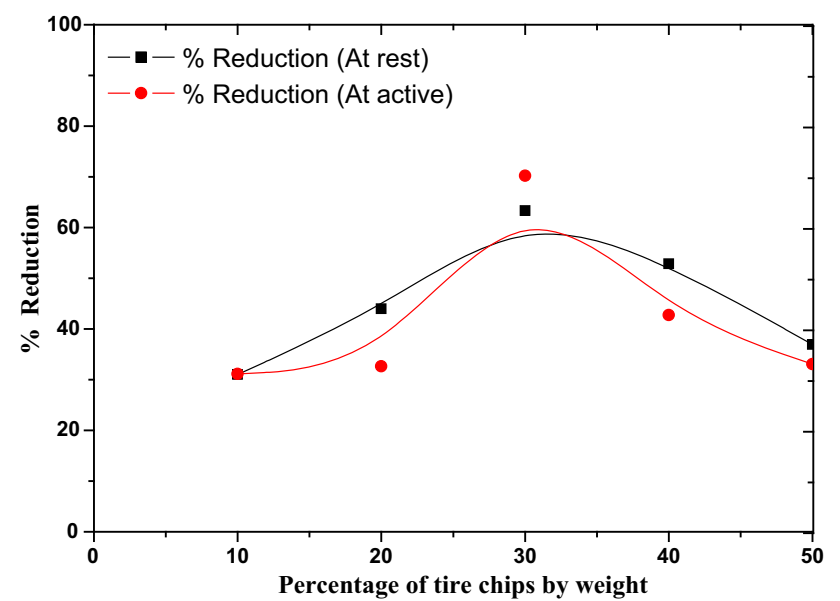

Fig. 17 Percentage reduction of measured maximum earth pressures with \% TC

Further it can also be noted that reduction of the horizontal displacements and earth pressures implies a lower design requirement which implies lesser dimensions of the retaining wall.

\section{Conclusions}

This paper presented experimental studies on the responses of laboratory scale retaining wall models with different STC mixtures as a backfill material. The displacements and lateral earth pressures responses along the height of the wall have been recorded during the testing. The results presented showed significant reduction in wall deformations and earth pressures for the model walls with STC mixtures as backfill. It can be concluded that the tire chips in the retaining wall backfill effectively work to reduced displacements and earth pressures by about $50-60 \%$ and thereby the reduction in the dimensions of the wall different loading scenarios. STC mixtures prove to be a cost effective light weight fill material and also reduce the demand for traditional materials with the replacement by recycled scrapped tire chips. The results obtained in the present study are only for the relative sizes of tire chips and retaining wall model adopted. It may be noted that the results might be influenced by the size of tire chips. Furthermore studies are needed on different sizes of tire chips and with different height of retaining walls for evolving general conclusions.

\section{References}

1. Humphrey DN, Sandford TC, Cribbs MM, Gharegrat H, Manion WP (1992) Tire chips as lightweight backfill for retaining wallsphase I. Dept. of Civil Engineering, University of Maine, Orono
2. Tweedie JJ, Humphrey DN, Sandford TC (1998) Tire shreds as retaining wall backfill, active conditions. J Geotech Geoenviron Eng (ASCE) 124(11):1061-1070

3. Cecich V, Gonzales L, Hoisaeter A, Williams J, Reddy K (1996) Use of shredded tires as lightweight backfill material for retaining structures. Waste Manag Res 14:433-451

4. Ravichandran N, Huggins L (2014). Applicability of shredded tire chips as a lightweight retaining wall backfill in seismic regions. In: Proceedings of geo-congress (GSP 234), ASCE, Atlanta

5. Graettinger AJ, Johnson PW, Sunkari P, Duke MC, Effinger J (2005) Recycling of plastic bottles for use as a lightweight geotechnical material. Manag Environ Qual 16(6):658-669

6. Eldin NN, Senouci AB (1992) Use of scrap tires in road construction. J Constr Eng Manag (ASCE) 118(3):561-576

7. Bosscher J, Edill TB, Kuraoka S (1997) Design of highway embankments using tire chips. J Geotech Geoenviron Eng 123(4):297-304

8. Vinot V, Singh B (2013) Shredded Tyre-Sand as fill material for embankment applications. J. Environ. Res. Develop. 7(4A): $1622-1627$

9. Bhalla G, Kumar A, Bansal A (2010) Performance of scrap tire shreds as a potential leachate collection medium. J Geotech Geol Eng 28(5):661-669

10. Warith MA, Evgin E, Benson PAS (2004) Suitability of shredded tires for use in landfill leachate collection systems. Waste Manag 24:967-979

11. Foose GJ, Benson CH, Bosscher PJ (1996) Sand reinforced with shredded waste tires. J Geotech Eng 122(9):760-767

12. Ghazavi M, Sakhil MA (2005) Influence of optimized tire shreds on shear strength parameters of sand. Int J Geomech (ASCE) 5(1):58-65

13. Gotteland P, Lambert S, Balachowski L (2005) Strength characteristics of tyre chips-sand Mixtures. Studia geotechnica et mechanica. 27(1-2):55-66

14. Marto A, Latifi N, Moradi R, Oghabi M, Zolfeghari S (2013) Shear properties of sand-tire chips mixtures. Electron J Geotech Eng 18(B):325-334

15. Rao GV, Dutta RK (2006) Compressibility and strength behavior of sand-tire chips mixtures. Geotech Geol Eng 24:711-724

16. Yang S, Lohnes RA, Kjartanson BH (2002) Mechanical Properties of Shredded Tires. Geotech Test Journal (GTJODJ) 25(1):44-52

17. Youwai S, Bergado DT (2003) Strength and deformation characteristics of shredded rubber tire-sand mixtures. Can Geotech J 40(2):254-264

18. Zornberg JG, Viratjandr C, Cabral AR (2004) Behavior of tire shred-sand mixtures. Can Geotech J 41(2):227-241

19. Anbazhagan P, Mamatha M, Soumyashree P, Sushyam N, Bharatha TP, Vivekan RW (2011) Laboratory characterization of tire crumbs soil mixture for developing low cost damping materials. Int J Earth Sci Eng 4(6):63-66

20. Sheikh MN, Mashiri MS, Vinod JS, Tsang HH (2013) Shear and Compressibility behavior of sand-tire crumb mixtures. J Mater Civ Eng 25:1366-1374

21. Wu WY, Benda CC, Cauley RF (1997) Triaxial determination of shear strength of tire chips. J Geotech Geoenviron Eng (ASCE) 123(5):479-482

22. Reddy KR, Stark T, Marella A (2010) Beneficial use of shredded tires as drainage material in cover systems for abandoned landfills. Pract Period Hazard. Toxic Radioact Waste Manag 14(1):47-60

23. Lee HJ, Roh HS (2006) The use of recycled tire chips to minimize dynamic earth pressure during compaction of backfill. Constr Build Mater J 21(5):1016-1026

24. Xiao M, Bowmen J, Graham M, Larralde J (2012) Comparison of seismic responses of geosynthetically reinforced walls with tire- 
derived aggregates and granular backfills. Mater Civ Eng (ASCE) 24:1368-1377

25. Huggins E, Ravichandran N (2011) Numerical study on the dynamic behavior of retaining walls backfilled with shredded tires. In: ASCE proceedings of GeoRisk 2011, June 26-28, 2011, Atlanta, Georgia d 2011000, Reston

26. Hazarika H, Kohama E, Sugano T (2008) Underwater shake table tests on waterfront structures protected with tire chips cushion. ASCE J Geotech Geoenviron Eng 134:1706-1719
27. Hazarika H, Yasuhara K (2007). Scrap tire derived geo materials-opportunities, Challenges. Taylor, and Francis, London

28. Reddy SB, Kumar DP, Krishna AM (2015) Evaluation of optimum mixing ratio of sand-tire chips mixture for geo-engineering applications. J Mater Civ Eng. http://ascelibrary.org/doi/abs/10. 1061/(ASCE)MT.1943-5533.0001335 